\title{
Designing a New System for Sharing Computer Science Teaching Resources
}

Mackenzie Leake

Stanford University

Stanford, CA 94305, USA

mleake@cs.stanford.edu

Colleen M. Lewis

Harvey Mudd College

Claremont, CA 91711, USA

lewis@cs.hmc.edu

Permission to make digital or hard copies of part or all of this work for personal or classroom use is granted without fee provided that copies are not made or distributed for profit or commercial advantage and that copies bear this notice and the full citation on the first page. Copynights for third-party components of this work must be honored.

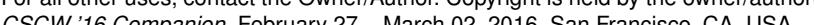
CSCW 1678 Comp

http://dx.doi.org/10.1145/2818052.2869109

\begin{abstract}
Many online communities for high school computer science teachers have been developed to help teachers connect with each other and share course materials. However, these sites have failed to meet teachers' needs and are widely underused. Creating new communities by repeating the design of existing sites will only require teachers to search additional sites to find what they need. Prior work has framed the inefficacy of these sites in terms of usability without exploring additional underlying problems that discourage teachers from using the sites. We interviewed teachers about their attitudes toward existing sites to further our understanding of these underlying problems. During interviews teachers said that finding relevant resources is difficult and contributing to these communities requires too much time. We propose a new design for a system that lowers the barrier to participation while providing teachers with improved access to each other's relevant course materials.
\end{abstract}

\section{Author Keywords}

Online communities; computer science education.

\section{ACM Classification Keywords}

H.5.m [Information interfaces and presentation (e.g., $\mathrm{HCl}$ )]: Miscellaneous 


\section{Teacher Information}

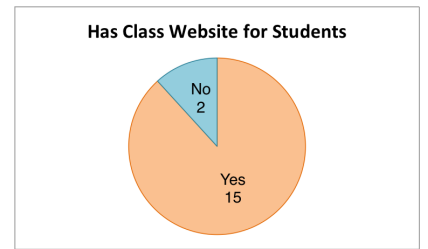

Figure 1: Most of the teachers we interviewed have class websites for their students.

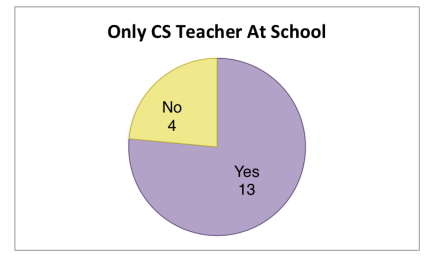

Figure 2: Many of the teachers we interviewed are the only CS teacher at their school.

\begin{tabular}{rr} 
Years & \# of Teachers \\
\hline $1-3$ & 6 \\
$3-6$ & 1 \\
$>6$ & 10 \\
\hline
\end{tabular}

Table 1: Interviewed teachers varied in the number of years of experience teaching CS.

\section{Introduction}

The National Science Foundation's CS10K project called for the training of 10,000 high school computer science (CS) teachers [2]. Training this many teachers is an enormous undertaking, and while in-person professional development has been shown to be effective in supporting teachers [8], these in-person events alone cannot provide teachers with everything they need. Many high schools only have a single CS teacher, so it can be difficult for teachers to find other teachers to turn to for help [3]. Online communities appear to be an obvious solution, but previous research has reported a number of usability problems with these online communities that prevent teachers from engaging fully with these sites [5, 7]. Helping teachers find resources is an important task, but additional online community sites should not be developed without first making substantial design changes.

Through conducting interviews with teachers, we have learned that many teachers find it challenging to find materials that match their students' current needs. Many teachers, however, have their own course websites, which they keep updated to provide materials for their students. These sites could be very beneficial for other teachers because the sites remain up-to-date and display materials within the context of the class. We discuss plans to build a system that supports teachers in finding relevant resources on other teachers' class websites.

\section{Methods}

We used the membership directory from the College Board Advanced Placement CS Teacher Community to find the names and schools of CS teachers. We found contact information for 149 of these teachers on their school websites and emailed them to request video interviews. We also posted a request on one Computer Science Teacher Asso- ciation chapter's email list. Each participant was offered $\$ 50$ for participating in an interview that lasted approximately one hour (ranging from 35 to 72 minutes). We conducted interviews with 17 teachers about their use of online teaching resources. We also interviewed five site moderators about the design goals of their sites. Additional information about our participants is provided in Figures 1 and 2 and Table 1. All participants consented to have their interviews recorded. We used these recordings to make transcripts, and we used Saturate App [9], a qualitative analysis tool, to tag quotations of interest in a process of open coding [4]. We then used these tags to identify a set of primary insights based upon the themes and variations among interview responses. We make design suggestions for a new site based on our interview responses.

\section{Interview Results}

During our interviews teachers emphasized a number of problems with these online communities.

Teachers Are Too Busy.

Many of the teachers we interviewed said that they are too busy to participate in online CS teacher communities:

My schedule is so crammed already just trying to teach five days a week (T1).

Many teachers said that these communities do not take their busy schedules into consideration in their designs:

There needs to be an understanding that the typical high school teacher is just going to be exhausted a lot of the time, and you might have the greatest thing in the world to show them, but if they feel like it's just going to make them more exhausted or it's gonna make more work for them, that may also kill the appeal (T2).

Some teachers view the time spent uploading materials 


\begin{tabular}{|l}
\hline Current Tools \\
There are a number of ex- \\
isting tools to support CS \\
teachers in finding resources, \\
including: \\
1. Google Custom Search \\
[1]. This tool has two \\
major problems: \\
(a) Teachers' course \\
sites are often \\
not returned near \\
the top of search \\
results. \\
(b) Search results are \\
not customized \\
to each teacher's \\
particular class- \\
room situation. \\
Online CS Teacher \\
Communities (Table 2). \\
Some problems with \\
these sites are: \\
(a) Teachers have \\
difficulty search- \\
ing the sites and \\
finding up-to-date \\
materials [6]. \\
(b) Many of these \\
sites are password \\
protected so their \\
contents are not \\
viewable within \\
general search \\
results. \\
Tom
\end{tabular}

to an external site as competing with the time they spend helping their students:

The time that I'm on this shared platform or sharing service is time I am not spending working with kids and working on developing lesson plans that benefit them (T3).

Teachers often feel that the time spent using existing tools takes time away from their main priority: their students.

It's Difficult Finding Relevant Resources.

Many teachers said that finding relevant resources is difficult using current tools:

It's really hard to find a lesson that will fit your class at the moment (T4).

To find relevant content many teachers seek resources directly from other teachers with similar classroom situations. Current tools do not enable teachers to search easily for other teachers' course websites.

\section{A New Solution}

We have designed a new website that addresses teachers' concerns about finding teaching resources (Figure 3). Our site, which will be called Shared CS Courses, makes teachers' class websites more accessible to other teachers. On class websites many teachers spend considerable time developing resources for their students. No current CS teacher sites facilitate teachers' ability to browse resources on other teachers' course websites (Table 2). During interviews teachers mentioned that having more information about another teacher's classes, personal background, and students would be helpful in assessing the relevance of another teacher's class materials.

Out of the 17 teachers we interviewed, 15 maintain course websites for their students, and 14 indicated their willingness to share these sites with other teachers publicly (Fig-

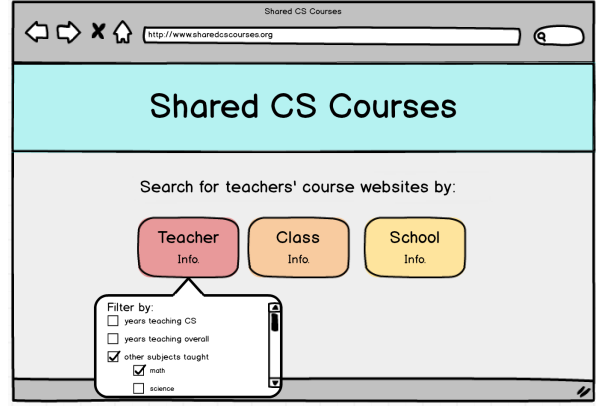

Figure 3: The homepage of Shared CS Courses allows teachers to search by teacher, class, or school information.

ure 1). To participate in our site, teachers will provide a biographical profile and a link to their website (Figure 4). This will require minimal effort from teachers, as they already update their websites for their students and can prioritize their time on providing these materials for their students.

Shared CS Courses will be different from other CS teacher sites because:

- Finding resources from similar teachers is easier because biographies facilitate finding others with similar backgrounds teaching similar courses.

- The site provides a curated collection of teachers' course sites rather than establishing and sustaining a community of teachers.

- Teachers can access updated materials throughout the year as their course progresses, and they can refer to these resources at any point.

- Contributing teachers can focus on preparing materials for their students rather than taking time to post on an external site. 


\begin{tabular}{|c|c|c|c|c|}
\hline \multirow[b]{2}{*}{ Community } & \multicolumn{4}{|c|}{ Biographical Info. on Current Sites } \\
\hline & Name & School & $\begin{array}{l}\text { Grad } \\
\text { Level }\end{array}$ & Courses \\
\hline $\begin{array}{l}\text { Alice } \\
\text { APCS } \\
\text { Greenroom } \\
\text { Scratch Ed }\end{array}$ & $\begin{array}{l}x \\
x \\
x\end{array}$ & $\begin{array}{l}x \\
x \\
x\end{array}$ & & $x$ \\
\hline
\end{tabular}

Table 2: Current sites do not offer enough biographical information about resource authors.

\begin{tabular}{|c|}
\hline Biographical Info. on Shared CS Courses \\
Teacher Information \\
\hline . Years teaching CS \\
- Years teaching overall \\
- Other subjects taught \\
- Induge degree in CS \\
- Other information \\
Class Information \\
- Grade level \\
- Number of students \\
- Curriculum \\
- Clagramming languages \\
- Class period length \\
School Information \\
- Location \\
- Years CS has been offered \\
- Type \\
- Number of CS teachers \\
- 2/4-year college matriculation rate
\end{tabular}

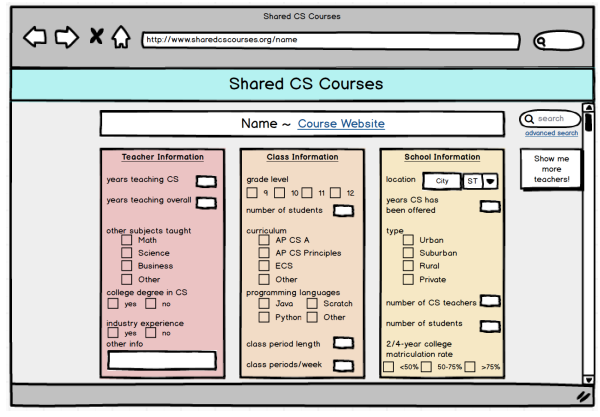

Figure 4: A teacher's page displays biographical information and a link to their course webpage.

\section{Future Work}

We plan to reach out to teachers personally to build their biographical profiles and link their course sites to our website. We will first contact one member in many different CSTA chapters to collect websites from teachers around the country, and then we will ask these teachers to encourage other teachers to contribute. We plan to use a mixed methods approach to assess the efficacy of the site. We will conduct additional interviews, survey a broader sample of teachers, and collect site analytics, such as click data and search queries. As we learn more about how teachers assess relevance and scale up the number of teacher sites indexed, we hope to use this information to return customized search results to teachers. We hope that our new site will inspire further research into providing teachers with better tools.

\section{REFERENCES}

1. Google Computer Science for High School Custom Search. http://www.cs4hs. com/resources/cscs.html.

2. Owen Astrachan, Jan Cuny, Chris Stephenson, and Cameron Wilson. 2011. The CS10K Project: Mobilizing the Community to Transform High School Computing.
In SIGCSE '11. ACM, New York, NY, USA, 85-86. DOI :http://dx.doi.org/10.1145/1953163.1953193

3. Jeanne Century, Mike Lach, Heather King, Sarah Rand, Courtney Heppner, Baker Franke, and Jean Westrick. 2013. Building an Operating System for Computer Science: Teacher Capacity Study. University of Chicago with UEI. http:

//outlier.uchicago. edu/computerscience/OS4CS/.

4. Juliet M. Corbin and Anslem L. Strauss. 2008. Basics of Qualitative Research. SAGE, Thousand Oaks, CA.

5. Christo Dichev and Darina Dicheva. 2012. Open Educational Resources in Computer Science Teaching. In SIGCSE '12. ACM, New York, NY, USA, 619-624. DOI: http://dx.doi.org/10.1145/2157136.2157314

6. Sally Fincher, Michael Kölling, lan Utting, Neil Brown, and Phil Stevens. 2010. Repositories of Teaching Material and Communities of Use: Nifty Assignments and the Greenroom. In ICER '10. ACM, New York, NY, USA, 107-114. DOI :

http://dx.doi.org/10.1145/1839594.1839613

7. Susan M. Mitchell and Wayne G. Lutters. 2006. Assessing the Value of Computer Science Course Material Repositories. In CSEETW '06. 2-2. DOI: http://dx.doi.org/10.1109/CSEETW. 2006.6

8. Lijun Ni, Mark Guzdial, Allison Elliott Tew, Briana Morrison, and Ria Galanos. 2011. Building a Community to Support HS CS Teachers: The Disciplinary Commons for Computing Educators. In SIGCSE '11. ACM, New York, NY, USA, 553-558. DOI : http://dx.doi .org/10.1145/1953163.1953319

9. Saturate. Saturate App. http://www. saturateapp.com/. 